\title{
BTK Inhibitor DTRMWXHS-12
}

National Cancer Institute

\section{Source}

National Cancer Institute. BTK Inhibitor DTRMWXHS-12. NCI Thesaurus. Code C130001.

An orally available inhibitor of Bruton's tyrosine kinase (BTK; Bruton

agammag lobulinemia tyrosine kinase), with potential antineoplastic activity. Upon administration, DTRMWXHS-12 inhibits the activity of BTK and prevents the activation of the B-cell antigen receptor (BCR) signaling pathway. This prevents both B-cell activation and BT K-mediated activation of downstream survival pathways. This leads to an inhibition of the growth of malignant B-cells that overexpress BTK. BTK, a member of the src-related BTK/Tec family of cytoplasmic tyrosine kinases, is overexpressed in B-cell malignancies; it plays an important role in the development, activation, signaling, proliferation and survival of B-lymphocytes. 